\title{
ANALYSIS OF MODELS AND ALGORITHMS FOR MEASURING THE AREA OF VINE LEAVES
}

\author{
Krasimira Georgieva, Miglena Kazakova, Zlatin Zlatev \\ Faculty of Technics and Technologies, Trakia University, Bulgaria \\ Graf Ignatiev 38, 8600 Yambol, Bulgaria, e-mail: zlatin.zlatev@trakia-uni.bg
}

\begin{abstract}
The area of the vine leaves is an important indicator for determining the quantity of leaf mass, making connections with the influence of the environment, improving the methods of growing the vineyards. Satellite and aviation measurements for now have the drawback that the images obtained are of low resolution and do not allow the measurement of the area of individual leaf. $A$ solution to this problem is the use of unmanned aerial vehicles, which provide digital images of a small height $(1-3 \mathrm{~m})$ and autonomous robots to navigate in the vineyards. These systems use video cameras operating in the visible, near infrared range and thermo cameras. The measurement of individual leaves and the search for links to the foliage and plant indicators is due to the fact that in order to do this when crawling the array, it is necessary to use low energy consumption devices. These devices also have poor computing resources. In this report a comparative analysis of 16 models describing the relationship between the area and the main dimensions of the leaf - long and short axis is made. Three of these models have been selected to describe this relationship with sufficient precision. They are compared with the 4 algorithm for measuring the area of the vine leaves. The results obtained show that the measurement error, the data processing time between the algorithms used and the models are comparable. The analyzes made suggest that the choice of a method for measuring the area of vine leaves depends on the desired accuracy, the time of receipt, the processing and the analysis of the results of what equipment the user has access to.
\end{abstract}

Keywords: Agricultural modeling, Area measurement, Vine leaves, Algorithm and models.

\section{INTRODUCTION}

Measurement of the area of vine leaves is a critical point in research aimed at managing irrigation, determining the impact of climate and slope environment, management systems in livestock breeding, looking for links between growing methods and plant development and their effectiveness. In the classical methods for determining the area of the vine leaves, a correlation between the weight of fresh or dry leaves with their area is used. This method is destructive because the measured leaves have to be cut off. This method is applicable after harvest.

Measurement of the area of individual leaves is an indicator used to determine the leaf index. Determining the area of individual vine leaves with remote measurement methods is a topical issue that has partial solutions.

Methods such as LIDAR, satellite and aviation measurements have the disadvantage that the resulting images are of low resolution and are applicable to determining the parameters of the entire area planted with vines.

Methods for measuring area of vine leaves include mechanical measuring instruments caliper, planner, coordinate networks, weighting method, regression models, image processing $[2,4,8]$.

Appropriate available tools are video cameras that can be equipment for autonomous robots crawling around the vineyard, as well as unmanned aerial vehicles capturing images from a small height $(1-3 \mathrm{~m})$. The software of such systems requires the use of algorithms to measure the area of the leaves [6]. 


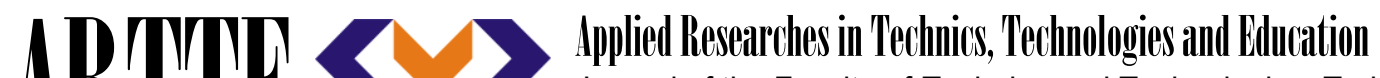 Journal of the Faculty of Technics and Technologies, Trakia University https://sites.google.com/a/trakia-uni.bg/artte/}

The use of these robotic technical devices to measure individual leaves and the demand for leaf linkages and agro-technical performance of plants on a real-time scale requires the use of low energy computing devices. These devices also have poor computing resources.

For this reason, it is necessary to use models and computational algorithms that can determine parameters of the vine array during robotic systems shooting [7,11].

The aim of the report is to make a comparative analysis of models and algorithms by which the area of individual vine leaves can be determined.

\section{EXPOSURE}

Measuring area of leaves by classical methods involves several ways. For the weighing method: weigh the leaves; the contour of the leaf is cut out on paper and this contour is cut out and weighed. Mathematical dependence determines the area of the leaf. Measurement can also be carried out by drawing the leaves, then by means of a special pricker, leaf discs are obtained and the area is calculated by the formula. Another known method calculates the relationship between the long and short axis of the leaf and calculates its area.

Another method used in this study is that of a planimeter. The length of the leaf $L$ is obtained from the top of the leaf until the beginning of its handle. Since the contour of the leaf, in many cases is irregular in shape, the width $W$ is determined: for the leaf in a more regular shape, the width $\mathrm{W}$ is taken to be equal to the length of the segment in the most protruding part of the leaf perpendicular to the major axis; for leaves with a very irregular shape, the width of the sheet $\mathrm{W}$ is assumed to be equal to the average width defined at several (three or four) consecutive points between the most convex and recessed portions in the middle of the leaf. In this case, the accuracy is increased compared to just one measurement of the small axis. Figure 1 shows the main dimensions of a vine leaf - length and width.

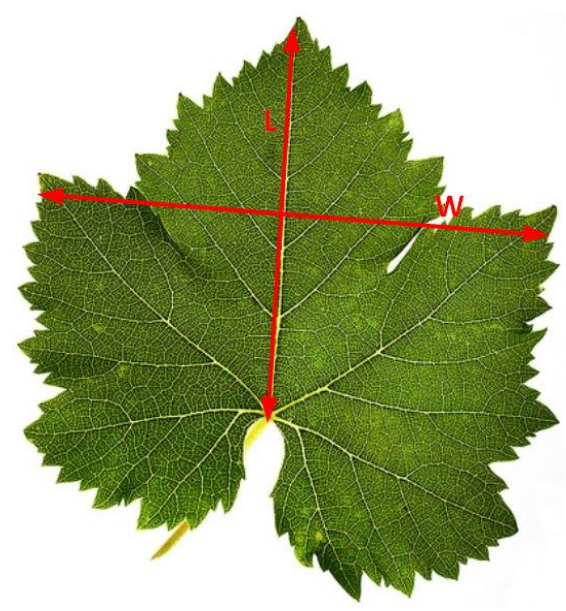

Figure 1. Main dimensions of vine leaves

In classical measurements, a link is sought between the length, width and area of the leaf in the form of a linear model of the type [9]:

$$
y=a x+b
$$

where $y$ is the area of the leaf and the independent variable $x$ is replaced by one of the length $L$ and the $W$ leaf widths: 


\section{ARTTIE $Y$}

Ipplied Researrores in Technics, Technologies and Bducation

Journal of the Faculty of Technics and Technologies, Trakia University https://sites.google.com/a/trakia-uni.bg/artte/

\begin{tabular}{|c|c|c|c|c|c|c|c|c|c|c|}
\hline \multicolumn{1}{|c|}{ Determination of area $A$ of vine leaves } \\
\hline $\mathrm{L}$ & $\mathrm{L}^{2}$ & $\mathrm{~L}^{2} \mathrm{~W}^{2}$ & $\mathrm{LW}$ & $\mathrm{W}$ & $\mathrm{W}^{2}$ & $1 / \mathrm{L}$ & $1 / \mathrm{L}^{2}$ & $1 /(\mathrm{LW})$ & $1 / \mathrm{W}$ & $1 / \mathrm{W}^{2}$ \\
\hline
\end{tabular}

In some cases, between the length and the width of the leaf with its area, a non-linear dependence is obtained, which is a prerequisite for searching for non-linear models that can accurately describe this dependence.

The well-known classic methods for determining the area of a leaf have the disadvantage that they are labor-intensive and require the meter's experience of realizing them.

Measurement methods using information about the long and short axis of the leaf can be realized by a computer program for measurement using color digital images. At today's level of development of science and technology, classical measurements are replaced by specialized tools and sophisticated methodologies of work. The main contribution to this is due to the development of digital image processing. Captured images serve as documentation, as well as for further processing and analysis. There are a number of reports that deal with the necessary equipment and techniques for quality capture.

In addition to the technical equipment in the literature, a number of image processing methods including white balance correlation and color rendering, correction of effects such as glare and noise [1, 3].

\section{MATERIAL AND METHODS}

The area of the vine leaves is determined by a planimeter. The applied measurement procedure is as follows: the contour of the leaf is copied to a pause; the planer is fixed to the working surface; the appliance is reset; the contour is traversed by the holder and the value on the scale is read; three consecutive measurements were made and their mean value was taken. The colorful digital images of the vine leaves are made with The Imaging Source DFK41AU02 (The imaging source Inc.) industrial video camera.

A Mitutoyo flat-parallel reference measure was used. After capture, the resulting images are processed with specially designed software. The RegionProps function is applied to black and white images, one of the results that returns the long and short axis of the object.

GNU Octave is used for algorithms realization and data analysis.

\subsection{Assessment of the applicability of vineyard area modeling models}

In addition to the coefficients of regression and errors, sensitivity assessment is also used to demonstrate the applicability of the model, and validation of this model is required. The sensitivity analysis is designed to determine how far the output dimensions of the model are influenced by moderate changes to the input dimensions of the model. Sensitivity testing can provide a general assessment of the accuracy of the model when used to evaluate alternative models as well as detailed information to overcome errors at different parameter values.

There are many linear and non-linear software (optimization) sensitivity analysis packages. They identify changes in target function values and unknown solutions to a given change in model input [10].

In order to assess the extent to which the model obtained describes the relationship between the main dimensions and the area of the leaves, the results of the studies and the model parameters obtained are used. Calculate the Student criterion, which at the available data has degrees of freedom $\mathrm{k}=\mathrm{n}-1$, where $\mathrm{n}$ is the number of experimental data. Compare the calculated and critical values determined tabularly to the Student criterion and assess whether the resulting model is adequate and can be applied to determine the area of the 


\section{ARTIL

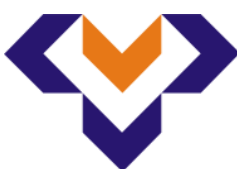 \\ Ipplied Researlohes in Technics, Technologies and Bductation \\ Journal of the Faculty of Technics and Technologies, Trakia University https://sites.google.com/a/trakia-uni.bg/artte/}

leaves. The results are confirmed by parameter deviations of $\pm 10 \%$ and the minimum and maximum error module values. This error is determined by the dependency:

$$
e=\left|\frac{A_{m}-A_{L}}{A_{L}}\right| \cdot 100, \%
$$

where $e$ is the error; $A_{m}$ - area of the leaf determined according to the model; $A L$ - actual area of the sheet determined by the reference method.

\section{2. $\quad$ Algorithms for determining area of vine leaves}

Image processing algorithms are selected that are easily accessible on the Internet and use basic recognition functions. Algorithms are used in their original form without modification.

Algorithm 1, the contour of the vine leaves is differentiated first from the other objects in the image - background, noises. The center of mass of this contour $(C)$ is then detected. Since the contour of the leaf is a figure with an irregular oval shape, the radii of this oval have different lengths. Determine the first radius of the contour, which is the distance $\left(x_{1}\right.$ to $\left.x_{c}\right)$. Then, at a certain angle $\left(\theta_{i}\right)$, all other radii - distances $\left(y_{i}\right.$ to $\left.y_{c}\right)$ are determined. The average radius of the contour is determined by the formula:

$$
R_{i}=\sqrt{\left(x_{i}-x_{c}\right)^{2}+\left(y_{i}-y_{c}\right)^{2}}, \quad i=1 \ldots 360
$$

The area of the leaf $A_{L}$ is defined as the sum of all the radii of the contour $\left(R_{i}\right)$ measured at a certain angle $\left(\theta_{i}\right)$ by the formula:

$$
A_{L}=\sum_{i=0}^{360} R_{i}\left(\theta_{i}\right)
$$

Algorithm 2, the contour of the vine leaves is differentiated first from the other objects in the image - background, noises. This algorithm works whether the contour coordinates are either clockwise or counter-clockwise. The area is determined by the formula:

$$
A_{L}=\left|\frac{\left(x_{1} y_{2}-y_{1} x_{2}\right)+\left(x_{2} y_{3}-y_{2} x_{3}\right)+\cdots+\left(x_{i} y_{i-1}-y_{i} x_{i-1}\right)}{2}\right|
$$

where $A_{L}$ is the area of the leaf; $x_{i}, y_{i}$ - coordinates of the points of the contour $i=1 \ldots n$, with $n$ being dependent on the number of points in the loop that are bounded by the BwBoundaries function.

Algorithm 3, the contour of the vine leaves is differentiated first from the other objects in the image - background, noises. This algorithm works whether the contour coordinates are either clockwise or counter-clockwise. $x_{i}, y_{i}$ are the coordinates of the outline points that are bounded by the BwBoundaries function. $d_{n}$ are the distances between two opposite points of the contour. The area of the leaf $A_{L}$ is determined by the following dependencies:

$$
\begin{aligned}
& d_{i}=\sqrt{\left(x_{1}-x_{i}\right)^{2}+\left(y_{1}-y_{i}\right)^{2}}, i=1 \ldots n \\
& A_{L}=\frac{\sum_{i=1}^{n} d_{i}}{2}
\end{aligned}
$$

IRTTE Vol. 6, No. 3, 2018 ISSN 1314-8788 (print), ISSN 1314-8796 (online), doi: 10.15547/artte.2018.03.002 


\section{ARITIE}

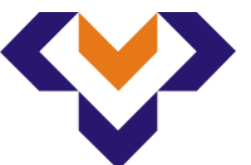

Ipplied Researrches in Technics, Technologies and Bduration

Journal of the Faculty of Technics and Technologies, Trakia University https://sites.google.com/a/trakia-uni.bg/artte/

Algorithm 4, the contour of the vine leaves is differentiated first from the other objects in the image - background, noises. The black and white image. All black pixels are counted using two nested cycles to determine the number of black and white pixels.

Figure 2 presents the preparatory steps and visualization of the results of the research algorithms for determining the area of vine leaves. The original image is converted to black and white, then filtered and all areas and noises removed. The results of the RegionProps function are presented. The results of the four algorithms are also visualized, in which case this presentation has only a visualization character because the algorithms are evaluated on a numerical basis.

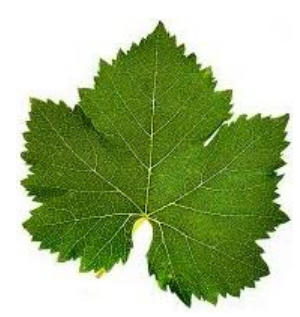

a) original image

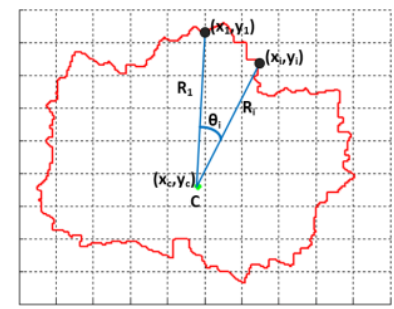

e) algorithm 1

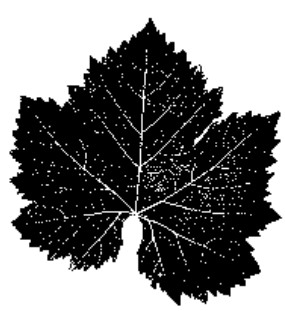

b) conversion to black and white

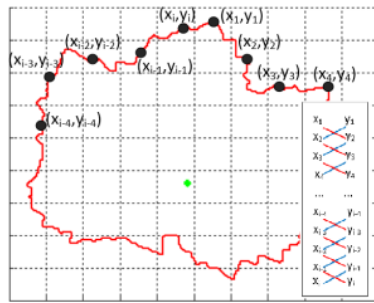

f) algorithm 2

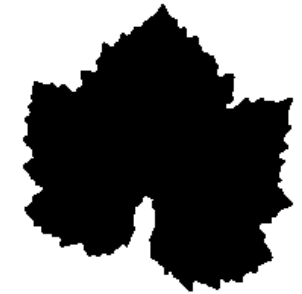

c) filtering and filling holes

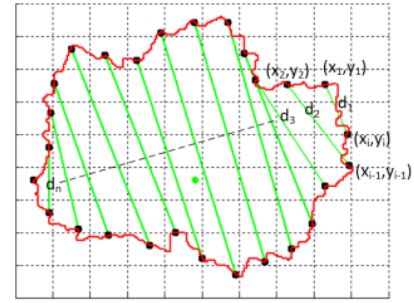

g) algorithm 3

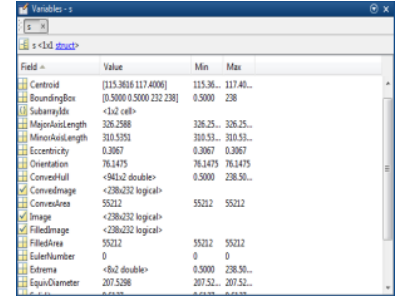

d) data obtaining

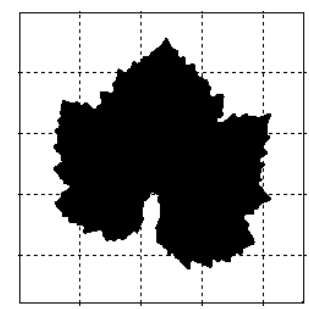

h) algorithm 4

Figure 2. Preparatory operations and algorithms for the determination of area of vine leaves

\section{RESULTS AND DISCUSSION}

\subsection{Analysis of models for determining the area of the vine leaves}

The correlation between the parameters of the vine leaves and their area values has been investigated. When using only the length $L$ and the width $W$ of the leaf, a correlation coefficient $R=0.93$ is obtained. Lower values are obtained using the reciprocal value of these parameters and the relationships between them $\mathrm{R}=0.85-0.89$.

Table 1 summarizes the correlation coefficients of some of the main parameters of the leaves, their dependence on their area.

Table 1. Correlation between the main dimensions and the area of the vine leaves

\begin{tabular}{|c|c|c|c|c|c|c|c|c|c|c|c|}
\hline Dimension & $\mathbf{L}$ & $\mathbf{L}^{2}$ & $\mathbf{L}^{2} \mathbf{W}^{2}$ & $\mathbf{L W}$ & $\mathbf{W}$ & $\mathbf{W}^{\mathbf{2}}$ & $\mathbf{1 / \mathbf { L }}$ & $\mathbf{1} / \mathbf{L}^{\mathbf{2}}$ & $\mathbf{1 / ( \mathbf { L } )}$ & $\mathbf{1} / \mathbf{W}$ & $\mathbf{1} / \mathbf{W}^{\mathbf{2}}$ \\
\hline $\begin{array}{c}\text { Correlation } \\
\text { with area }\end{array}$ & 0,931 & 0,922 & 0,927 & 0,946 & 0,925 & 0,929 & $-0,923$ & $-0,900$ & $-0,890$ & $-0,890$ & $-0,853$ \\
\hline
\end{tabular}

A study was conducted on the relationship between the main parameters, their ratios and the area of the leaves.

Figure 3 shows examples of the line between the main dimensions of a large axis $(L)$, a short axis $(\mathrm{W})$ and the area of the leaf $(\mathrm{A})$.

IRTIIE Vol. 6, No. 3, 2018 ISSN 1314-8788 (print), ISSN 1314-8796 (online), doi: 10.15547/artte.2018.03.002 


\section{IRTTIE}

Ipplied Researrothes in Technics, Technologies and Educiation Journal of the Faculty of Technics and Technologies, Trakia University https://sites.google.com/a/trakia-uni.bg/artte/
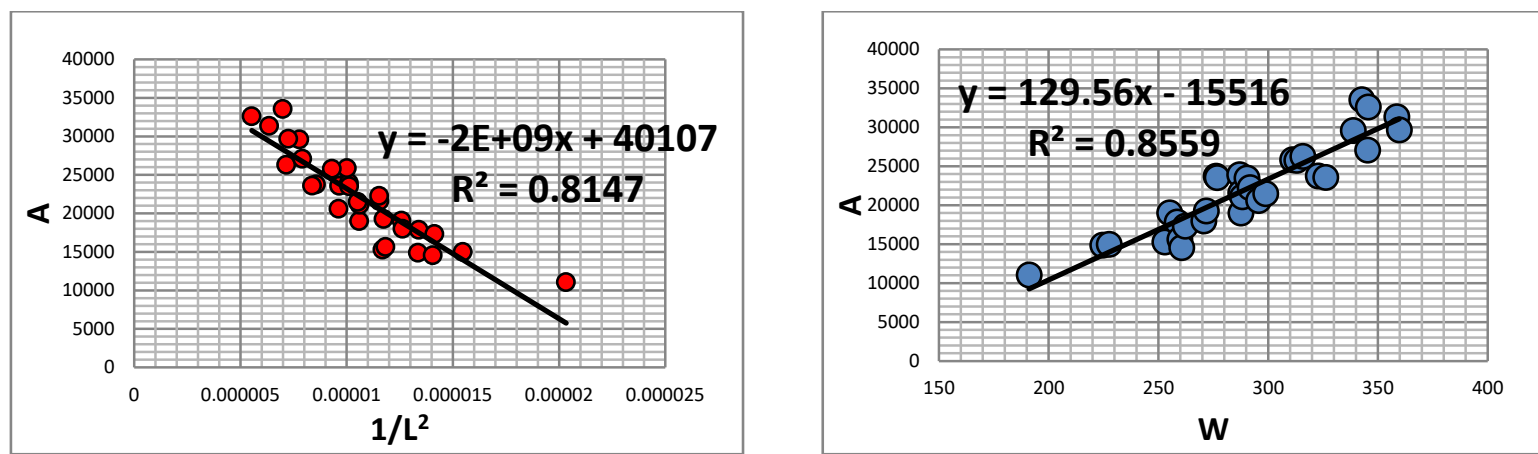

Figure 3. Relationship between area and main leaf sizes

Linear dependencies have been employed as the literature references $[5,9]$ indicate that it is convenient for practical purposes to use the most simplified models, such as the linear ones. Table 2 presents the linear models describing the relationship between the main leaf dimensions and those of its area. The test was performed with a confidence interval of $95 \%$ and a maximum permissible error $\varepsilon=0.05$. As with the correlation coefficients, low regression coefficients $R^{2}=0.65-0.86$ are obtained here using the reciprocal values of the main dimensions and their relations. For practical purposes, it is recommended to use patterns in which only the length of the leaf is involved, since it is much easier to define than the width. The length $L$ is the distance from the top of the leaf to its handle. For completeness here are presented dependencies mediated the other parameters of the leaf, their proportions in relation to its area. The coefficient of regression when used in linear models of only length $L$ is $R^{2}=0.81-0.87$, indicating that it is applicable for practical purposes. Other authors $[5,7,9]$ also have high error rates in determining such patterns for determining the area of leaves of different types of plants - aubergine, roses, sugar cane, Indian pepper. The model's quality is assessed by the calculated values of the statistical variables. A model is better if the following conditions are met: The first condition is a high value of the regression coefficient $R^{2}$, a second condition for model quality is a low SSE and RMSE value (sum of squares of errors and root of the error rate).

Table 2. Evaluation of Linear Models

\begin{tabular}{|c|c|c|c|c|}
\hline Dimension & Model $\mathbf{y = a x + b}$; Area A=y & $\mathbf{R}^{2}$ & SSE & RMSE \\
\hline $\mathrm{x}=\mathrm{L}$ & $\mathrm{y}=119 \mathrm{x}-15380$ & 0,867 & $1,31 \mathrm{E} 8$ & 2089 \\
\hline $\mathrm{x}=\mathrm{L}^{2}$ & $\mathrm{y}=0,181 \mathrm{x}+3830$ & 0,849 & $1,484 \mathrm{E} 8$ & 2224 \\
\hline $\mathrm{x}=1 / \mathrm{L}$ & $\mathrm{y}=-1 \mathrm{E} 7 \mathrm{x}+5942$ & 0,851 & $4,771 \mathrm{E} 9$ & $1,261 \mathrm{E} 4$ \\
\hline $\mathrm{x}=1 / \mathrm{L}^{2}$ & $\mathrm{y}=-1,69 \mathrm{E} 9 \mathrm{x}+4,011 \mathrm{E} 4$ & 0,815 & $9,843 \mathrm{E} 8$ & 5728 \\
\hline $\mathrm{x}=\mathrm{W}$ & $\mathrm{y}=129,6 \mathrm{x}-1,552 \mathrm{E} 4$ & 0,856 & $1,418 \mathrm{E} 8$ & 2174 \\
\hline $\mathrm{x}=\mathrm{W}^{2}$ & $\mathrm{y}=0,226 \mathrm{x}+2699$ & 0,862 & $1,026 \mathrm{E} 8$ & 2214 \\
\hline $\mathrm{x}=1 / \mathrm{W}$ & $\mathrm{y}=-9 \mathrm{E} 6 \mathrm{x}+55245$ & 0,789 & $1,839 \mathrm{E} 6$ & 0,0002476 \\
\hline $\mathrm{x}=1 / \mathrm{W}^{2}$ & $\mathrm{y}=-1,185 \mathrm{E} 9^{*} \mathrm{x}+3,706 \mathrm{E} 4$ & 0,728 & $1,387 \mathrm{E}-10$ & $2,15 \mathrm{E}-6$ \\
\hline $\mathrm{x}=\mathrm{L}+\mathrm{W}$ & $\mathrm{y}=57,13 \mathrm{x}-1,24 \mathrm{E} 4$ & 0,885 & $1,13 \mathrm{E} 8$ & 1941 \\
\hline $\mathrm{x}=\mathrm{L}^{2}+\mathrm{W}^{2}$ & $\mathrm{y}=0,105 \mathrm{x}+2465$ & 0,894 & $1,041 \mathrm{E} 8$ & 1862 \\
\hline $\mathrm{x}=1 / \mathrm{L}^{2}$ & $\mathrm{y}=-0,2968 \mathrm{E} 9 \mathrm{x}+3.92 \mathrm{E} 4$ & 0,800 & $1,968 \mathrm{E} 8$ & 2561 \\
\hline$\left.+\mathrm{W}^{2}\right)$ & $\mathrm{y}=0,212 \mathrm{x}+2375$ & 0,896 & $1,026 \mathrm{E} 8$ & 1850 \\
\hline $\mathrm{x}=\mathrm{LW}$ & $\mathrm{y}=1,048 \mathrm{E}-06 \mathrm{x}+1,239 \mathrm{E} 4$ & 0,860 & $1,378 \mathrm{E} 8$ & 2143 \\
\hline $\mathrm{x}=\mathrm{L}^{2} \mathrm{~W}^{2}$ & $\mathrm{y}=129,6 \mathrm{x}-1.552 \mathrm{E} 4$ & 0,856 & $1,418 \mathrm{E} 8$ & 2174 \\
\hline $\mathrm{x}=1 /(\mathrm{L}+\mathrm{W})$ & $\mathrm{y}=-1 \mathrm{E} 9 \mathrm{x}+39043$ & 0,796 & 0,07558 & 0,05019 \\
\hline $\mathrm{x}=1 /(\mathrm{LW})$ & $\mathrm{y}=-4,666 \mathrm{E} 13 \mathrm{x}+2,89 \mathrm{E} 4$ & 0,646 & $3,481 \mathrm{E} 8$ & 3407 \\
\hline $\mathrm{x}=1 /\left(\mathrm{L}^{2} \mathrm{~W}^{2}\right)$ & \multicolumn{3}{|c}{} \\
\hline
\end{tabular}

IRTIIE Vol. 6, No. 3, 2018 ISSN 1314-8788 (print), ISSN 1314-8796 (online), doi: 10.15547/artte.2018.03.002 


\section{ARTTE $Y$}

Ipplied Researldeses in Technics, Technologies and Bduration Journal of the Faculty of Technics and Technologies, Trakia University https://sites.google.com/a/trakia-uni.bg/artte/

In some data, there is a non-linear relationship between the base size and the area and the question is, in which case it is necessary to compare at least four non-linear models to specify which one describes the data sufficiently.

Figure 4 shows an example of using a non-linear model when describing the relationship between the square of the leaf width $\mathrm{W}^{2}$ and its area $\mathrm{A}$. The Curve Fitting Tool is used, which is available in most versions of Matlab.

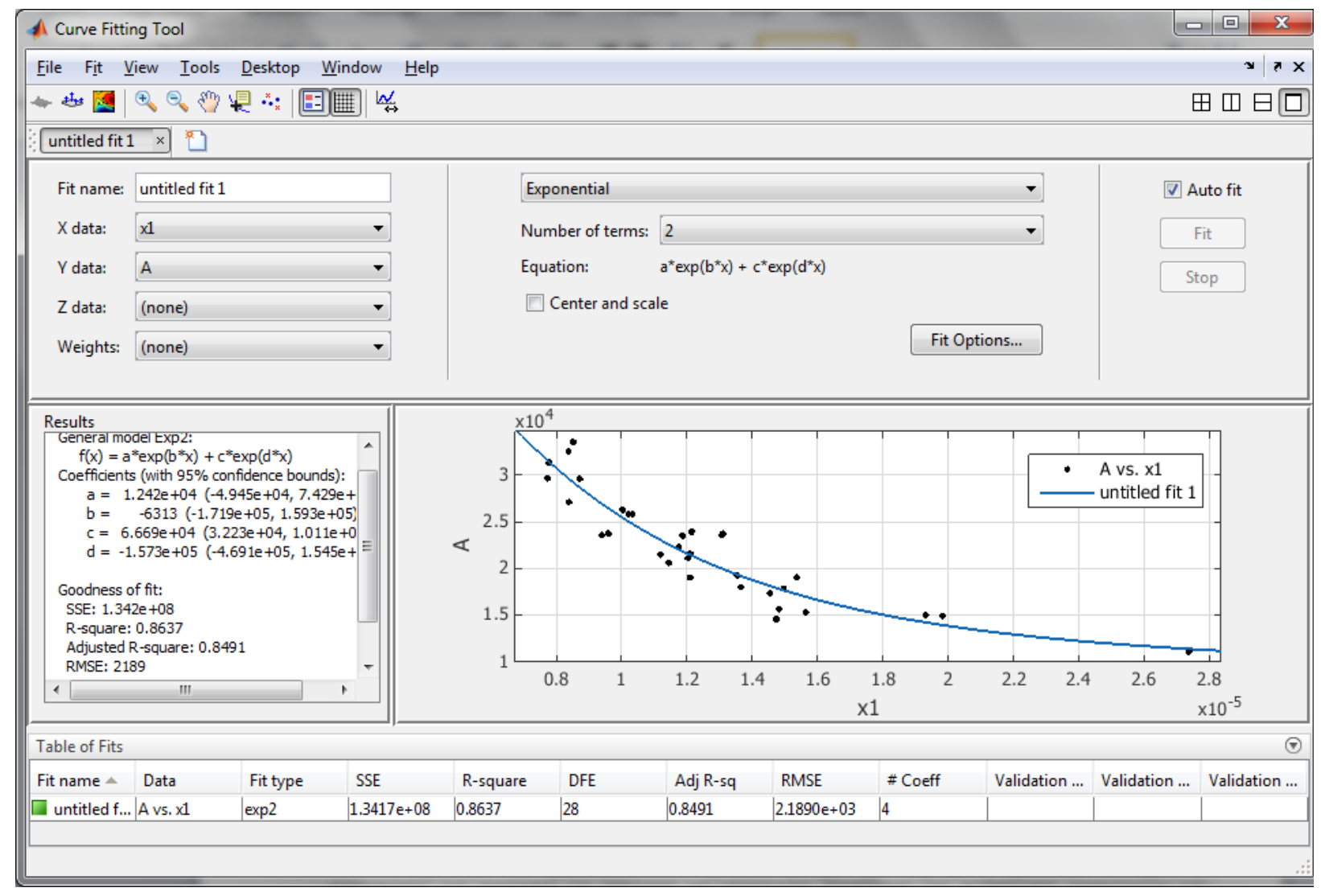

Figure 4.

Example of a non-linear relationship between the width $W^{2}$ and the area of the leaf $A$

Using a model of type $y=a \cdot \exp (b . x)$, the value of $R^{2}=0.834$ decreases compared to the linear model $\left(R^{2}=0.862\right)$, error values are also increased $S S E=1.636 E 8, R M S E=2335$.

The use of a more sophisticated exponential model with four coefficients of $y=a$.exp (b.x)+c.exp(d.x) also does not describe with higher accuracy than linear data. The value of the regression coefficient has a minimum increase $R^{2}=0.864$. Errors also reduce with minimum SSE=1.342E8 and RMSE=2189.

\subsubsection{Sensitivity assessment of models}

Figure 5 presents graphically the results of the adequacy assessment of the models using as a background the measurements of the leaf length $L$. As can be seen from the chart with the greatest sensitivity to change of parameters, the model uses the reciprocal value of leaf length $1 / L$ as an independent variable. 


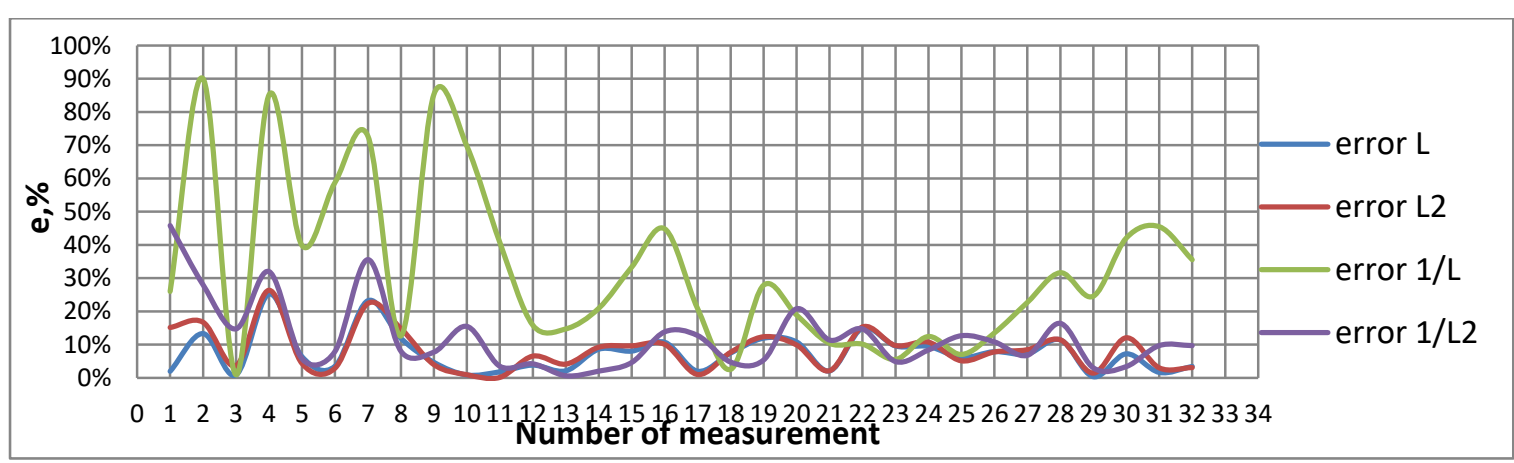

Figure 5. The error module curves e, $\%$ with a deviation from the experimental curve $\pm 10 \%$

The results are also confirmed by the parameter deviation data presented in Table 3 by $\pm 10 \%$ and the minimum and maximum error module values. Low values of this error are obtained using the large axis of the leaf as an independent variable in the model.

Table 3. Sensitivity analysis of models with deviations from the experimental curve $\pm 10 \%$

\begin{tabular}{|c|r|r|r|r|}
\hline Dimension & \multicolumn{1}{|c|}{$\mathrm{x}=\mathrm{L}$} & \multicolumn{1}{c|}{$\mathrm{x}=\mathrm{L}^{2}$} & \multicolumn{1}{c|}{$\mathrm{x}=1 / \mathrm{L}$} & \multicolumn{1}{c|}{$\mathrm{x}=1 / \mathrm{L}^{2}$} \\
\hline Model & $\mathrm{y}=119 \mathrm{x}-15380$ & $\mathrm{y}=0,181 \mathrm{x}+3830$ & $\mathrm{y}=-1 \mathrm{E} 7 \mathrm{x}+5942$ & $\mathrm{y}=-1,69 \mathrm{E} 9 \mathrm{x}+4,011 \mathrm{E} 4$ \\
\hline $\mathbf{a}_{\min }$ & 111 & 0,163 & $-9,00 \mathrm{E}+06$ & $-1,86 \mathrm{E}+09$ \\
\hline $\mathbf{a}_{\max }$ & 127 & 0,199 & $-1,10 \mathrm{E}+07$ & $-1,52 \mathrm{E}+09$ \\
\hline $\mathbf{b}_{\min }$ & 13842 & 3447 & 5348 & $3,61 \mathrm{E}+04$ \\
\hline $\mathbf{b}_{\max }$ & 16918 & 4213 & 6536 & $0 \%$ \\
\hline $\mathbf{e}_{\min } \%$ & $2 \%$ & $0 \%$ & $1 \%$ & $46 \%$ \\
\hline $\mathbf{e}_{\max }, \%$ & $22 \%$ & $29 \%$ & $91 \%$ & 04 \\
\hline
\end{tabular}

The smallest sensitivity to changing the model parameters relative to the other models studied is that using the length $\mathrm{L}$ without other transformations. The maximum error is $\mathrm{e}=22 \%$. The next most important model with a low sensitivity $\mathrm{e}=29 \%$ is the one using the square of the long axis of the leaf.

\subsubsection{Assessing the adequacy of the models}

The evaluation of the adequacy of the models was done with samples of vine leaves that did not participate in the initial receipt of the models. Table 4 presents the results of the verification. Linear models of the type $A_{m}=a . x+b$ were used, where the independent variable $x$ was replaced with any of the lengthwise transformations of the vine leaf $L$; the coefficients $a$ and $b$ are from the model shown above in the material. With $A_{\text {real }}$ the area of the leaves is measured by the reference method.

Table 4. Results of model adequacy test

\begin{tabular}{|c|c|c|c|c|c|}
\hline t-Test: Paired Two Sample for Means & $\mathrm{X}=\mathrm{L}$ & $X=L^{2}$ & $x=1 / L$ & $X=1 / L^{2}$ & A real \\
\hline Mean & 22293,64 & 22094,59 & 26010,72 & 22631,65 & 27612,12 \\
\hline Variance & 8386496,49 & 7812695,30 & 8648702,48 & 8845857,03 & 62541142,94 \\
\hline Observations & 25 & 25 & 25 & 25 & 25 \\
\hline Pearson Correlation & 0,89 & 0,89 & $-0,81$ & 0,89 & - \\
\hline Hypothesized Mean Difference & 0 & 0 & 0 & 0 & - \\
\hline df & 24 & 24 & 24 & 24 & - \\
\hline t Stat & $-4,85$ & $-4,96$ & $-0,77$ & $-4,59$ & - \\
\hline$P(T<=t)$ one-tail & 0,00 & 0,00 & 0,23 & 0,00 & - \\
\hline t Critical one-tail & 1,71 & 1,71 & 1,71 & 1,71 & - \\
\hline $\mathrm{P}(\mathrm{T}<=\mathrm{t})$ two-tail & 0,00 & 0,00 & 0,45 & 0,00 & - \\
\hline t Critical two-tail & 2,06 & 2,06 & 2,06 & 2,06 & - \\
\hline
\end{tabular}

IRTIIE Vol. 6, No. 3, 2018 ISSN 1314-8788 (print), ISSN 1314-8796 (online), doi: 10.15547/artte.2018.03.002 


\section{ART'TE

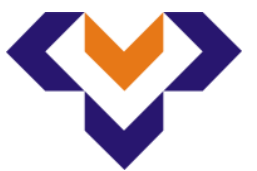 \\ Ipplied Reseirlches in Technics, Technologies and Eductition \\ Journal of the Faculty of Technics and Technologies, Trakia University https://sites.google.com/a/trakia-uni.bg/artte/}

As with the studied linear models using data on leaf length and width, the algorithms can also be compared to the areas they calculated and those obtained by the standard method. Figure 6 shows examples of comparison of areas defined by algorithms 1 and 4 and those determined by the reference method. Algorithm 4 shows a higher regression coefficient $R^{2}$ relative to algorithm 1.
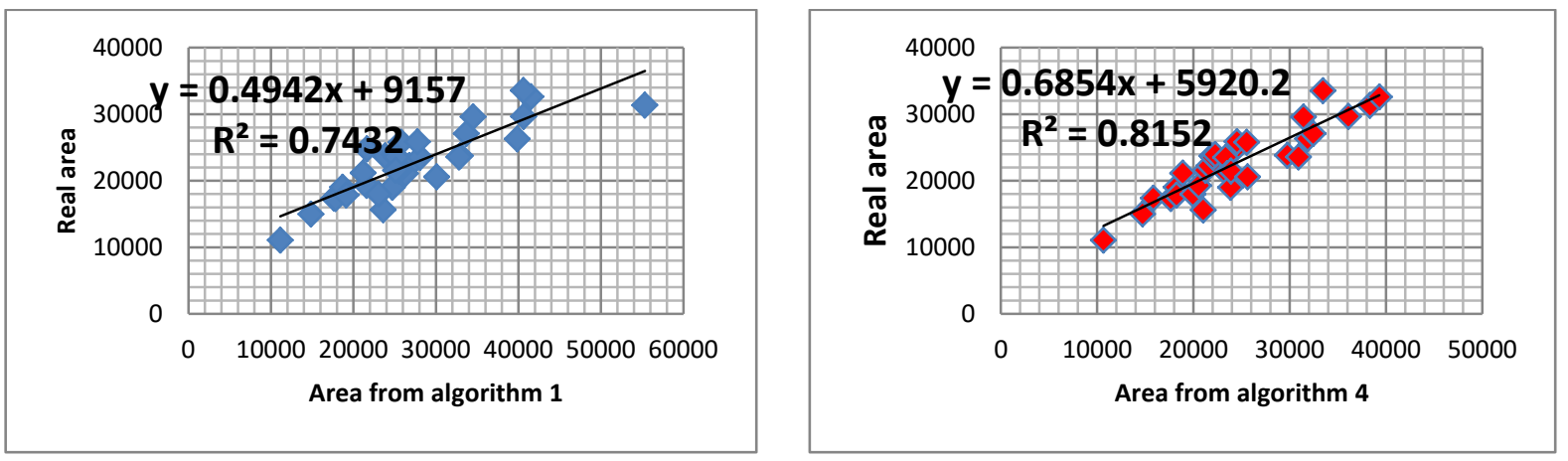

Figure 6. Comparison of areas defined by algorithms 1 and 4

Figure 7 shows a runtime diagram of the algorithms. The processing time is when using color digital images at a resolution of 320x240 pixels. The longest processing time is algorithm 4 . The reason for its slower operation is the use of nested cycles to determine the number of black pixels in the image. When defining algorithms, these visualizations have been removed from programs that only evaluate processing time, but not visualization, as it is not of interest in this study.

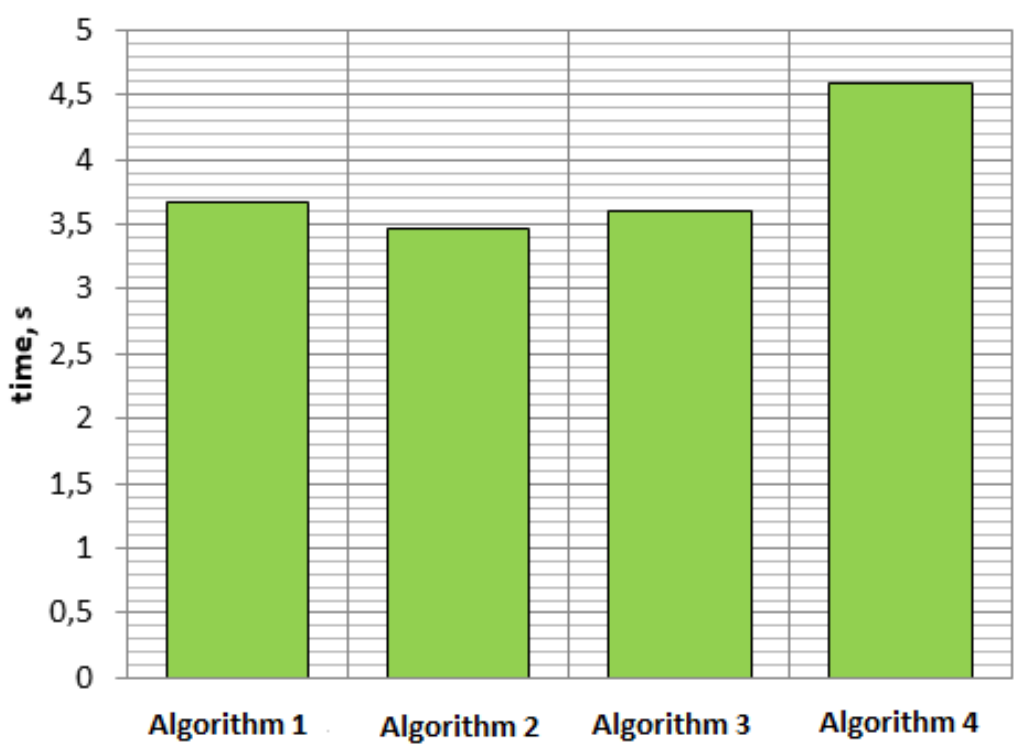

Figure 7. Time to process data from algorithms 


\subsection{A comparative analysis of algorithms and models for determining area of vine leaves}

The comparative analysis between the algorithms and models used is based on the criteria: regression coefficient $R^{2}$ describing the relationship between the areas measured by the algorithm or model and the area measured by the reference method; the processing time, image analysis, and results are determined; the results are compared by level of significance $\mathrm{p}$-value determined by the ttest function in MS Excel. For convenience, a nomenclature of the algorithms and models studied is presented in Table 5.

Table 6 presents the results of comparative analysis of models and algorithms by regression coefficient and processing time. It can be seen that when using the models the processing time is significantly less - within $0.6 \mathrm{~s}$ compared to the algorithms. Also, when using models, higher regression coefficients $R^{2}=0.82-0.87$ are obtained, whereas for algorithms this coefficient is $R^{2}=0.75-0.82$.

Table 5. Introduced nomenclature

\begin{tabular}{|c|c|}
\hline Parameter & Name \\
\hline$A 1$ & Algorithm 1 \\
\hline$A 2$ & Algorithm 2 \\
\hline$A 3$ & Algorithm 3 \\
\hline A4 & Algorithm 4 \\
\hline$M 1$ & $x=L ; y=119 x-15380$ \\
\hline$M 2$ & $x=L^{2} ; y=0,181 x+3830$ \\
\hline$M 3$ & $x=1 / L^{2} ; y=-1,69 E 9 x+4,011 E 4$ \\
\hline$A L$ & Area of vine leaves, measured by reference method \\
\hline
\end{tabular}

Table 6. A comparative Analysis of Algorithms and Models

\begin{tabular}{|c|r|r|r|r|r|r|r|}
\hline & \multicolumn{1}{|c|}{ A1 } & \multicolumn{1}{c|}{ A2 } & \multicolumn{1}{c|}{ A3 } & \multicolumn{1}{|c|}{ A4 } & \multicolumn{1}{c|}{ M1 } & M2 & \multicolumn{1}{|c|}{ M3 } \\
\hline $\mathrm{R}^{2} \mathrm{c} \mathrm{A}_{\mathrm{L}}$ & 0,748 & 0,804 & 0,789 & 0,815 & 0,867 & 0,849 & 0,815 \\
\hline $\mathrm{t}_{\text {обр }} \mathrm{S}$ & 3,681 & 4,592 & 3,610 & 3,463 & 0,612 & 0,601 & 0,607 \\
\hline $\mathrm{SSE}$ & $2,14 \mathrm{E} 08$ & $1,17 \mathrm{E} 08$ & $1,79 \mathrm{E} 08$ & $1,57 \mathrm{E} 08$ & $1,31 \mathrm{E} 08$ & $1,48 \mathrm{E} 08$ & $9,84 \mathrm{E} 08$ \\
\hline $\mathrm{RMSE}$ & 2668 & 2353 & 2240 & 2284 & 2089 & 2224 & 5728 \\
\hline
\end{tabular}

The regression coefficient and the processing time are not a sufficient criterion for assessing the methods used to obtain the area of vine leaves. Processing time up to 5 seconds makes these algorithms and models fast enough to get the necessary information.

The next comparison that is made is the $p$-value significance level, the results of this analysis are presented in Table 7.

Table 7. A comparative analysis between algorithms and models by level of significance

\begin{tabular}{|c|c|c|c|c|c|c|c|c|}
\hline & $\mathbf{A 1}$ & $\mathbf{A 2}$ & $\mathbf{A 3}$ & $\mathbf{A 4}$ & $\mathbf{M} 1$ & $\mathbf{M 2}$ & $\mathbf{M} 3$ & $\mathbf{A}_{\mathbf{L}}$ \\
\hline $\mathbf{A} 1$ & $\mathrm{X}$ & $\mathbf{0 , 0 0 0 0}$ & $\mathbf{0 , 0 0 0 0}$ & $\mathbf{0 , 0 0 0 1}$ & $\mathbf{0 , 0 0 7 9}$ & $\mathbf{0 , 0 0 7 8}$ & $\mathbf{0 , 0 1 0 7}$ & $\mathbf{0 , 0 0 0 0}$ \\
\hline A2 & $\mathbf{0 , 0 0 0 0}$ & $\mathrm{X}$ & $\mathbf{0 , 0 0 0 6}$ & $\mathbf{0 , 0 0 0 0}$ & 0,2313 & 0,2414 & 0,2301 & $\mathbf{0 , 0 4 0 7}$ \\
\hline A3 & $\mathbf{0 , 0 0 0 0}$ & $\mathbf{0 , 0 0 0 6}$ & $\mathrm{X}$ & $\mathbf{0 , 0 4 1 9}$ & $\mathbf{0 , 0 4 4 9}$ & $\mathbf{0 , 0 4 5 0}$ & 0,0533 & $\mathbf{0 , 0 0 0 2}$ \\
\hline A4 & $\mathbf{0 , 0 0 0 1}$ & $\mathbf{0 , 0 0 0 0}$ & $\mathbf{0 , 0 4 1 9}$ & $\mathrm{X}$ & 0,1189 & 0,1230 & 0,1263 & $\mathbf{0 , 0 0 3 0}$ \\
\hline M1 & $\mathbf{0 , 0 0 7 9}$ & 0,2313 & $\mathbf{0 , 0 4 4 9}$ & 0,1189 & $\mathrm{X}$ & 0,4759 & 0,5992 & 0,6219 \\
\hline M2 & $\mathbf{0 , 0 0 7 8}$ & 0,2414 & $\mathbf{0 , 0 4 5 0}$ & 0,1230 & 0,4759 & $\mathrm{X}$ & 0,5514 & 0,6551 \\
\hline M3 & $\mathbf{0 , 0 1 0 7}$ & 0,2301 & 0,0533 & 0,1263 & 0,5992 & 0,5514 & $\mathrm{X}$ & 0,5595 \\
\hline $\mathbf{A}_{\mathbf{L}}$ & $\mathbf{0 , 0 0 0 0}$ & $\mathbf{0 , 0 4 0 7}$ & $\mathbf{0 , 0 0 0 2}$ & $\mathbf{0 , 0 0 3 0}$ & 0,6219 & 0,6551 & 0,5595 & $\mathrm{X}$ \\
\hline
\end{tabular}




\section{AR'TIE $Y$ > \\ Ipplied Researlohes in Technics, Technologies and Bductation \\ Journal of the Faculty of Technics and Technologies, Trakia University \\ https://sites.google.com/a/trakia-uni.bg/artte/}

The analysis by level of significance shows that the closest measurement with the area data of the vine leaves by the reference method are those determined by the four algorithms. The use of models shows a significant statistical difference $p=0.56-0.62$. The results obtained show that using computer measurement methods, it is appropriate to use algorithms instead of approximating patterns. Patterns have multiple benefits - less processing time and fewer computational resources to obtain results because they use a simplified mathematical apparatus. The high degree of approximation, since only one major leaf size is used - its long axis is one of the reasons for not high measurement accuracy. These models are more suitable for classical measurements of the area of the leaves using millimeter paper or other measuring tools, which greatly reduces the workload and time for determining the area of the leaves.

\section{CONCLUSION}

The report provides a comparative analysis of models and algorithms for measuring the area of vine leaves.

The advantage of the models is that they use a large and small axis of the sheet and the algorithms do not require a large computational resource and have sufficient performance to use during the digital image of the vine leaves through the mobile robot computing resources or unmanned aerial vehicle.

From the analysis of 16 models describing the relationship between the large, small axis and the area of the vine leaves, 3 have been selected, showing a high coefficient of regression (over 0.75 ), small errors and slight sensitivity in changing the model parameters.

The coefficient of regression $R^{2}$ obtained in the algorithms is $0.78-0.80$ and when using models it is $0.82-0.87$. The low error rates for both methods reach $2-9 \%$. These results show that algorithms and models are comparable to results.

The choice of a method for measuring the area of vine leaves depends on the desired accuracy, the time of receipt, processing and analysis of the results of what equipment the user has access to.

\section{ACKNOWLEDGEMENTS}

The studies presented in the report are supported under Project 6.OUP/ 25.04.2017 "Building a Laboratory for Photogrammetric and Remote Measurement Methods".

\section{REFERENCES}

[1] Berriss W., Acquisition of skin wound images and measurement of wound healing rate and status using colour image processing, 2000.

[2] Eftekhari M., B. Kamkar, M. Alizadeh, Prediction of leaf area in some Iranian table grape (Vitis vinifera L.) cuttings by a non-destructive and simple method, Science Research Reporter, Vol. 1, No. 3, 2011, pp. 115-121.

[3] Hamilton A., Digital Photography in Wound Management. WoundsWest, 2010, p. 14.

[4] Jadon M., A novel method for leaf area estimation based on Hough transform, Journal of Multimedia Processing and Technologies, Vol. 9, No. 2, 2018, pp .33-44.

[5] Lopes C., P. Pinto, Easy and accurate estimation of grapevine leaf area with simple mathematical models, Vitis, Vol. 44, No.2, 2005, pp. 55-61.

[6] Lopes, C. A. Torres, R. Guzmán, J. Graça, M. Reyes, G. Vitorino, R. Braga, A. Monteiro, A. Barriguinha, Using an unmanned ground vehicle to scout vineyards for non-intrusive estimation of canopy features and grape yield, GiESCO Mendoza, 2017, pp. 16-21.

IRTTIE Vol. 6, No. 3, 2018 ISSN 1314-8788 (print), ISSN 1314-8796 (online), doi: 10.15547/artte.2018.03.002 


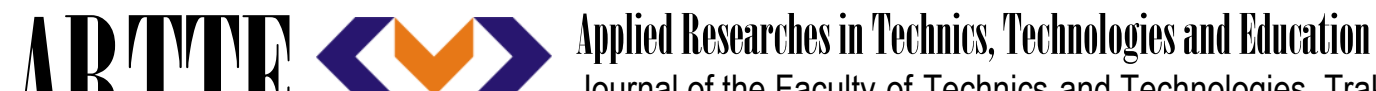 Journal of the Faculty of Technics and Technologies, Trakia University https://sites.google.com/a/trakia-uni.bg/artte/}

[7] Matese A, S. Di Gennaro, Technology in precision viticulture: a state of the art review, International Journal of Wine Research, Vol. 7, 2015, ISSN 1179-1403, pp. 69-81.

[8] Ozdemir G., A. Sessiz, F. Pekitkan, Precision viticulture tools to production of high quality grapes, Scientific Papers. Series B, Horticulture. Vol. LXI, 2017, pp. 209-218.

[9] Pandey S., H. Singh, A simple cost-effective method for leaf area estimation, Journal of Botany, Vol. 2011, pp. 1-6.

[10] Valov N., Control of the regime parameters for convective drying of fruits and vegetables, PhD thesis, University of Ruse, Bulgaria, 2014.

[11] Zarco-Tejada P., N. Hubbard, P. Loudjani (2014). Precision agriculture: an opportunity for eu farmers - potential support with the cap 2014-2020. 